\title{
VARIABILIDADE PLUVIOMÉTRICA NO MUNICÍPIO DE JUIZ DE FORA-MG NO PERÍODO DE 1910-2018: INVESTIGAÇÃO A PARTIR DA TÉCNICA DO BOX PLOT
}

\author{
OLIVEIRA, Thiago Alves - thiagooliveirageo2014@yahoo.com.br \\ Universidade Federal de Juiz Fora/ UFJF
}

TAVARES, Camila de Moraes Gomes - camila.tardeli.tavares@gmail.com
Universidade Federal de Juiz Fora/ UFJF

SANCHES, Fabio - fsanches.73@gmail.com

Universidade Federal de Juiz Fora/ UFJF

FERREIRA, Cassia de Castro Martins - cassia.castro@ufjf.edu.br

Universidade Federal de Juiz Fora/ UFJF

\begin{abstract}
RESUMO: Discutir a variabilidade da precipitação se torna importante na medida em que essa é a principal forma de reposição hídrica na Terra, além disso pode influenciar as atividades humanas, em função de sua intensa variabilidade, tanto temporal quanto espacial. Para compreender a variabilidade das chuvas em Juiz de Fora- MG no intervalo temporal compreendido entre 1910-2017 utilizou-se a técnica do box plot na perspectiva de identificar intervalos de anos padrão (normal, seco, úmido, super-seco, superúmido), para inferir a respeito dos eventos anormais de chuvas e correlacioná-los aos modos de variabilidade das chuvas sobre a área estudada. Não foi possível identificar a correspondência entre a classificação dos anos padrão e a ocorrência dos fenômenos El Niño e La Niña. Na correlação das décadas com a ODP (Oscilação Decadal do Pacífico) é possível verificar que este indicador climático oceânico não apresenta correlação como modo de variabilidade direta com as chuvas para a áreas estudada. Os dados trimestrais apontam para uma sazonalidade bem marcada das chuvas em Juiz de Fora, com mais de $80 \%$ da precipitação anual, em média, concentrada nos períodos de primavera (OND) e verão (JFM).
\end{abstract}

PALAVRAS-CHAVE: Variabilidade pluviométrica, Box plot, Precipitação, ENOS

PLUVIOMETRIC VARIABILITY IN THE CITY OF JUIZ DE FORA-MG DURING 1910-2018: INVESTIGATION FROM THE BOX PLOT TECHNIQUE

\begin{abstract}
The debate about precipitation variability becomes important as this is the main form of water replacement on Earth, in addition it can influence human activities, due to its intense variability, both temporal and spatial. To understand the variability of rainfall in Juiz de Fora-MG between 1910-2017, the box plot technique was used to identify standard year intervals (normal, dry, humid, super-dry, super-humid) and correlate them to the variability of rainfall over the studied area. It was not possible to identify the correspondence between the "standard years" and the occurrence of the ENSO phenomena. In the correlation of the decades with the PDO (Decadal Pacific Oscillation) it was possible to verify that this oceanic climatic indicator did not present any correlation as a mode of direct variability associated with rainfall for the studied area. The quarterly data pointed to a well-marked seasonality of rainfall in Juiz de Fora, with more than $80 \%$ of annual rainfall, on average, concentrated in the spring (OND) and summer (JFM) periods
\end{abstract}

KEYWORDS: Rainfall variability, Box plot, Precipitation, ENSO.

\section{INTRODUÇÃO}

Diante dos efeitos que as precipitações têm no espaço, a depender de sua intensidade, compreender a dinâmica das chuvas sobre uma determinada 
área, assim como os modos de variabilidades que influenciam as precipitações torna-se um fator a ser considerado nas tomadas de decisões que envolvem essas áreas sobre as quais busca-se estudar. Em termos gerais, compreender os mecanismos que influenciam na dinâmica, variabilidade, intensidade e frequência das chuvas, torna-se possível obter a previsibilidade das chuvas. Tais informações auxiliam na agricultura, evitando a perda da plantação devido à ausência ou abundância de chuvas, devido a ação de modos de variabilidade que podem intensificar eventos de seca ou intensas precipitações, e auxiliam nas políticas públicas voltadas para os espaços urbanos, uma vez que se pode tomar decisões em prol de minimizar os impactos pluviométricos nas cidades, como as enchentes e os movimentos de massa.

A precipitação influencia na dinâmica e no manejo agropecuário, assim como no cotidiano dos citadinos, pois, com o crescimento das cidades ocorrido nas últimas décadas, as precipitações tem impactado de diversas maneiras as atividades humanas, principalmente quando associada a eventos extremos.

Baldo (2006) salienta que a

Precipitação pluviométrica, merece uma ênfase especial, uma vez que a sua distribuição no espaço e sua irregularidade no tempo tornam-se relevantes, não apenas do ponto de vista climático, mas principalmente pelas repercussões na agricultura e nos problemas de ordem econômica delas advindos, no abastecimento de água, na produção de energia hidrelétrica, nos processos físicos e em outras formas de vida (BALDO, 2006, p.2).

Com o passar dos anos, o estudo sobre as metodologias de análise das precipitações sofreu diversas mudanças, alterações e proposições. As alterações de caráter metodológico acompanharam o próprio desenvolvimento da climatologia geográfica, uma vez que, até o início do século XX a climatologia possuía suas bases conceituais na concepção de Julius Hann, na qual o clima e as manifestações de seus elementos deveriam ser entendidos como o "conjunto dos fenômenos meteorológicos que caracterizam a condição média da atmosfera sobre cada lugar da Terra" (MENDONÇA e DANNI-OLIVEIRA, 2007, p.14). Nesta concepção, as anomalias e os eventos extremos, responsáveis por impactos ao meio e à sociedade, seriam desconsiderados do contexto climático.

Durante o século XX, Max Sorre discutiu a concepção de clima revisando a ideia de Hann e considerou que o clima consiste nos

Estados da atmosfera em sua totalidade e não o estado médio, englobando toda a série desses estados, o que significa que não deixa de lado os tipos excepcionais que as médias mascaram completamente" (BARROS; ZAVATINI, 2009, p. 256).

Dentro da climatologia brasileira, por sua vez, Monteiro $(1971 ; 1973)$ apresenta a perspectiva da análise rítmica, aproximando-se da concepção climática de Max Sorre, discutindo o clima a partir de uma sucessão de tipos de tempos que caracterizariam o ritmo climático.

Segundo Monteiro (1971, p. 4) "O conceito de ritmo, expressão da sucessão dos estados atmosféricos, conduz implicitamente, ao conceito de 
"habitual" uma vez que há variações e desvios que geram diferentes graus de distorções até atingir padrões "extremos"". Monteiro (1971) destaca ainda para a importância de uma estatística minuciosa sendo "possível selecionar alguns anos representativos do padrão habitual e dos extremos" (MONTEIRO, 1971, p. 9).

Nesse sentido, Tavares (1976) esclarece que "os diversos climas teriam, durante as várias estações do ano, tipos de tempo característicos, que se sucederiam de forma definida, caracterizando cadeias de tipo de tempo" (TAVARES, 1976, p. 80).

O autor, por sua vez, aponta para a necessidade de estabelecer parâmetros para a análise dos anos padrão, que corresponderia a um ano em que "a distribuição da precipitação anual de um determinado lugar é semelhante à distribuição das precipitações médias, obtidos através de vários anos para esse local" (TAVARES, 1976, p. 81).

Além dos anos com padrão normal (habitual), Tavares (1976) ainda esclarece que os

\begin{abstract}
Anos padrões "secos" ou "chuvosos" não se referem aos totais anuais de chuvas à distribuição delas no decorrer do ano. O ano padrão seco caracterizar-se-ia por uma distribuição das precipitações que apresentasse um grande desvio em relação aos dados médios, em função de períodos com intensa falta de chuvas, enquanto 0 ano padrão chuvoso deveria suas discrepâncias ao excesso de chuva em relação aos dados mais frequentes. (TAVARES, 1976, p. 81).
\end{abstract}

Neste sentido, a técnica do box plot, segundo Galvani e Luchiari (2004), aparece como uma alternativa aos estudos sobre a variabilidade pluviométrica, pois permite identificar "intervalos para a determinação de anos com padrão normal, seco, úmido, super-seco, super- úmido de maneira rápida e objetiva" (GALVANI \& LUCHIARI, 2004, p.5708).

Segundo Schneider (2014) e Nascimento Júnior (2017), os estudos pautados em análises estatísticas permitem a melhor compreensão e classificação dos dados em longas séries temporais. A partir da aplicação do desvio padrão e análises sazonais da precipitação, Berezuk \& Garcia (2001) observaram aumento das precipitações durante a estação chuvosa (dez/jan/fev) e diminuição das chuvas na primavera (set/out/nov) para a baixa bacia do rio Pardo (MS). Chierice (2013), por sua vez, observou leve tendência à diminuição das precipitações anuais ao analisar a variabilidade das chuvas na bacia do rio Mogi-Guaçu entre os anos 1975 e 1999.

Utilizando-se dos métodos estatísticos (desvio padrão, quantil, fórmula de Sturges e box plot), para a identificação de anos padrão e posterior análise rítmica, Oliveira (2016) analisou a gênese e o ritmo das precipitações na bacia do Rio Preto MG/RJ, para os anos de 2006, 2007, 2008, destacando que a utilização dos anos-padrão "deu subsídios a uma compreensão do ritmo das chuvas nas escalas anuais, mensais e diárias" (OLIVEIRA, 2016, p.139).

Schneider e Silva (2014), analisaram a precipitação na Microrregião de Dourados-MS, no período de 1980 a 2012 utilizando o box plot como metodologia. Os autores destacam que 
O uso da técnica Box Plot merece relevância na medida em que sua importância permitiu discutir os resultados sob o ponto de vista temporal, quantitativo e qualitativo. Na verdade, a técnica converge com os interesses da Climatologia Geográfica evidenciando tendências, condições habituais e, ao mesmo tempo, extremos. Aplicada ao estudo de chuvas a técnica permitiu compreender o comportamento rítmico das chuvas (SCHEIDER; SILVA, 2014, p. 144).

Schneider (2014) ainda aponta para a importância de estudos pautados na variabilidade pluviométrica, pois as chuvas na microrregião de Dourados representam impactos tanto positivos como negativos para a produtividade agrícola, além disso, aponta para uma tendência de redução das chuvas na primavera.

Na perspectiva de análise da variabilidade das chuvas numa dada região, é de substancial importância avaliar a participação dos fenômenos moduladores interanuais e interdecenais, como o fenômeno El Niño Oscilação Sul (ENOS) e a Oscilação Decadal (Decenal) do Pacífico (ODP), por exemplo (GRIMM, 2009; KAYANO; ANDREOLI, 2009).

Para Grimm (2009) o ENOS representa a principal fonte de variabilidade interanual da precipitação no Brasil, uma vez que o fenômeno, tanto e sua fase positiva (El Niño), como na negativa (La Niña), modifica o padrão circulatório da atmosfera sobre a América do Sul, influenciando na dinâmica das massas de ar atuantes sobre o continente e, consequentemente, nas chuvas.

A ODP também é responsável por modular as chuvas, porém, em uma escala de tempo de décadas visto que suas fases (positivas e negativas) compreendem intervalos de tempo em torno de 20 a 30 anos (MANTUA et al., 1997; KAYANO; ANDREOLI, 2009).

Dessa forma, o estudo de longas séries temporais, sobretudo com base em técnicas estatísticas permite identificar os padrões pluviométricos de uma localidade/região. Assim, o objetivo do presente trabalho foi analisar as precipitações na cidade de Juiz de Fora no período de 1910-2017 a partir da técnica estatística box plot inferindo, assim, considerações a respeito dos eventos anormais de chuvas, o comportamento e os eventos moduladores da variabilidade das chuvas.

\section{CARACTERIZAÇÃo DA ÁREA DE ESTUDO}

Juiz de Fora, cidade média localizada na região Zona da Mata do estado de Minas Gerais (Figura 1), com população estimada em 568.873 habitantes (IBGE,2020), a qual foi caracterizada segundo Ab'Sáber (2007) por morrarias arredondadas e recobertas por vegetação de Mata Atlântica - Domínio dos Mares de Morros e, conforme Eduardo (2018) tem em sua área urbana uma amplitude altimétrica em torno de 300 metros.

Como discorre Abreu (1998), a localização do estado de Minas Gerais faz com que o mesmo sofra interferência tanto de fenômenos meteorológicos tropicais como aqueles os advindos das latitudes médias, com isso, com relação 
às condições climáticas observa-se "duas estações bem definidas podem ser identificadas: uma seca e uma chuvosa" (ABREU, 1998, p.17).

Neste sentido, Reboita et al (2015) destacam que o estado de Minas Gerais se insere em um clima de monção, uma vez que as chuvas se concentram em mais de $70 \%$ no período do verão austral, pois nessa época do ano "os sistemas atmosféricos migram para sul e com isso há uma intensificação da temperatura do ar e da atividade convectiva nas cercanias do Trópico de Capricórnio" (REBOITA et al., 2015, p.207).

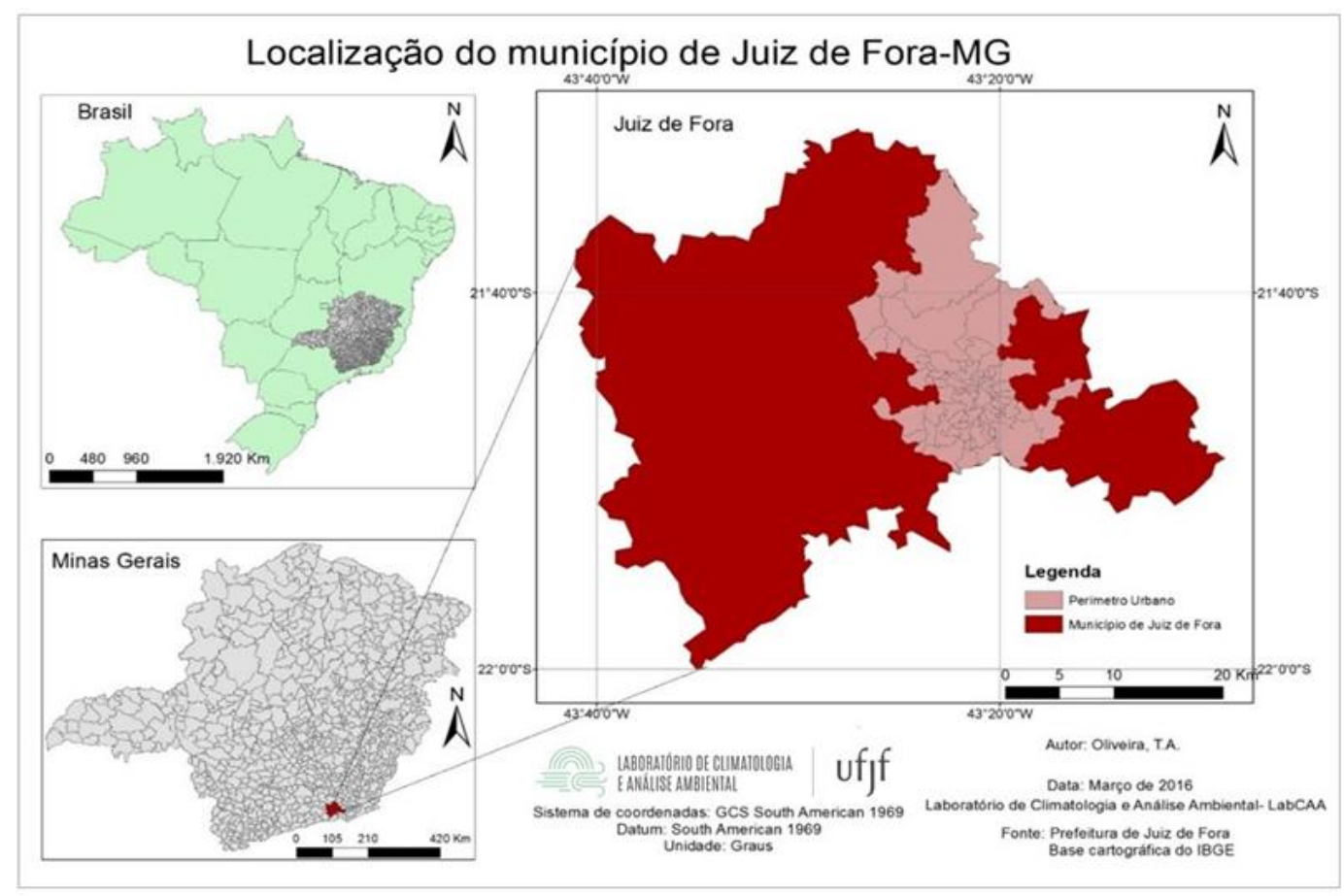

Figura 1 - Juiz de Fora/MG- Localização. Fonte: Organizado pelos autores.

As precipitações no município de Juiz de Fora (Figura 2) são em média de 1494,87 mm ao ano (dados do período de 1910 a 2017) dividindo-se em uma estação chuvosa, que se estende de outubro a março, e outra estação seca, de abril a setembro. Neste contexto, Ferreira (2012, p.959) ainda ressalta que "que os meses de abril e setembro se comportam como um período de transição entre a estação seca e a chuvosa e o contrário", observando-se a atuação de sistemas atmosféricos que promovem tanto precipitações, como períodos de seca durante esses dois meses. 


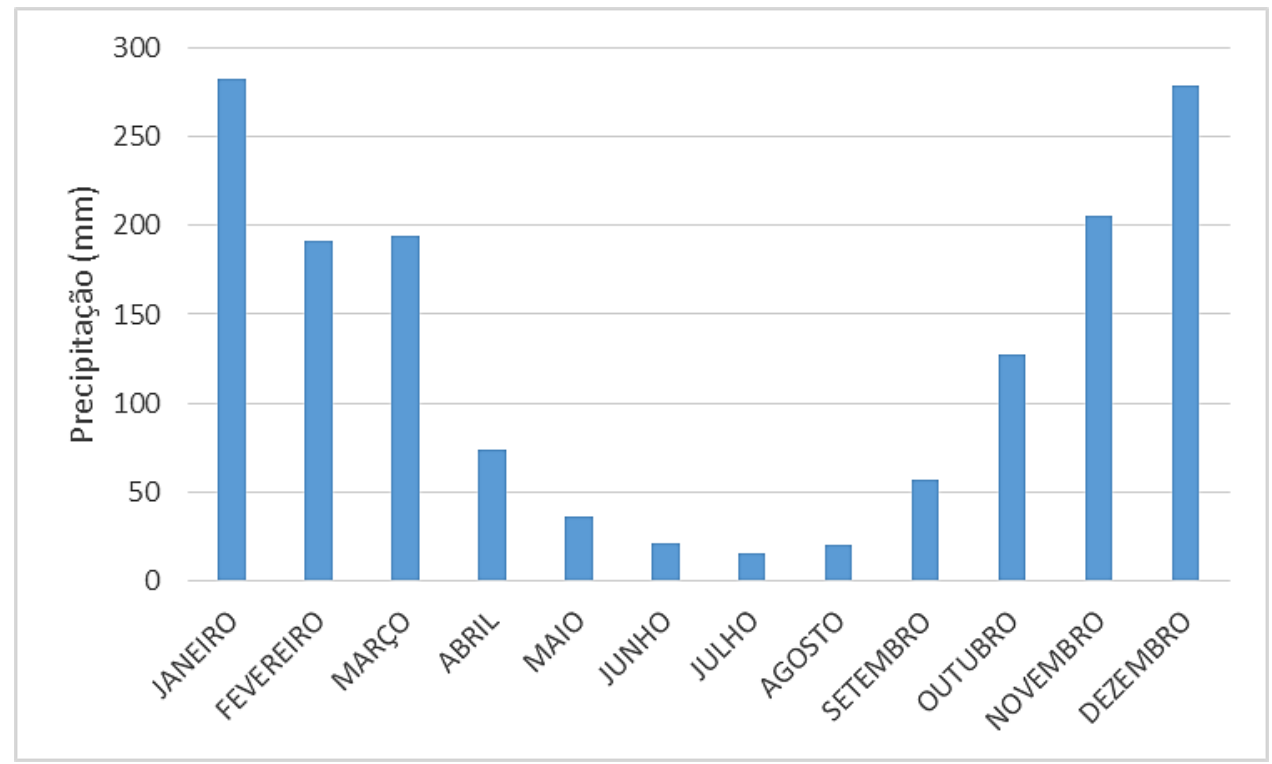

Figura 2 - Médias pluviométricas mensais de Juiz de Fora - 1910-2017. Elaborado pelos autores. Fonte dos dados: LabCAA, 2018.

Dentre os principais sistemas atmosféricos atuantes, podemos apontar a Massa Tropical Atlântica (mTa), a Massa Polar Atlântica (mPa) e, consequentemente, os sistemas frontais, além da participação da Zona de Convergência do Atlântico Sul (ZCAS) e da Zona de Convergência de Umidade (ZCOU) na dinâmica das chuvas na região de estudo (CAVALCANTI et al, 2009). A Massa Tropical Atlântica (mTa), originada no Anticiclone Subtropical do Atlântico Sul (ASAS), possui características atmosféricas quente e seca, tendo uma maior atuação na estação fria, pois durante o inverno esse centro ciclônico aproxima-se do continente sul-americano intensificando sua influência no Brasil (BORSATO, 2016) e diminuindo a sua atuação no verão, período no qual o anticiclone se afasta do continente e perde abrangência.

Por se tratar de um sistema originado em um anticiclone, as suas características durante o período de atuação, principalmente no inverno, são de atmosfera estável. Essa dinâmica dificulta os movimentos ascendentes do ar promovendo, consequentemente, baixos totais pluviométricos, exceto em áreas de influência orográfica (REBOITA et al 2015; BORSATO, 2016). A Massa de ar Tropical Atlântica (mTa) aparece como a principal massa de ar atuante no sudeste brasileiro ao longo do ano, porém, nos meses quentes, ela se se afasta para o oceano Atlântico (BORSATO, 2016; OLIVEIRA, 2016).

Já a Massa Polar Atlântica (mPa), consiste em um sistema de alta pressão, gerador de estabilidade atmosférica, com exceção à sua zona frontal, que avança pelo território brasileiro impondo suas características físicas. Durante o período do inverno, sua atuação é mais intensa pelo interior do continente (BORSATO, 2016).

Os sistemas frontais estão associados à atuação da Massa Polar Atlântica ( $\mathrm{mPa}$ ) pois "em sua borda, no contato com os sistemas atmosféricos tropicais, configuram-se extensas zonas de pressão relativamente baixa e intensa convergência, usualmente chamada de frente polar" (GALVANI; AZEVEDO, 
2012). Em função dessa convergência do ar mais quente observa-se a ocorrência de chuvas frontais na vanguarda da massa Polar atlântica (mPa).

Nos períodos de primavera e verão, parte da umidade produzida na região Amazônica é transportada para o sul e o sudeste através dos Jatos de Baixos Níveis (JBN) a leste dos Andes. Estas condições, associadas a sistemas frontais localizados no Atlântico, favorecem a formação das Zonas de Convergência do Atlântico Sul (ZCAS) que aparecem como uma das principais fontes de umidade e, consequentemente, precipitação que atinge principalmente a região Sudeste do Brasil (REBOITA et al., 2015; SANTOS; FIALHO, 2016; OLIVEIRA, 2016).

Nesse sentido, compreender a variabilidade natural das variáveis climáticas assim como identificar os eventos que fogem dessa variabilidade normal e os fenômenos moduladores é de fundamental importância na perspectiva de pensar o espaço sobre o qual esses eventos atuam.

\section{MATERIAIS E MÉTODOS}

Para este trabalho, a metodologia foi dividida em cinco etapas.

Em um primeiro momento foi realizado um levantamento bibliográfico acerca da variabilidade pluviométrica, destacando os procedimentos metodológicos para a classificação dos dados, bem como os resultados encontrados.

Posteriormente, em uma segunda parte, prosseguiu-se para os levantamentos dos dados pluviométricos mensais e anuais. Estes foram disponibilizados pelo Laboratório de Climatologia e Análise Ambiental da Universidade Federal de Juiz de Fora - LabCAA/UFJF (Figura 02) para o período de 1910 a 2017. Ressalta-se que a estação mudou seu local de observação por três vezes ao longo desse período, passando de áreas centrais da cidade até ser levada, em 1972, para o campus da UFJF, a $937 \mathrm{~m}$ de altitude, no bairro Martelos (STAICO, 1976).

No terceiro momento, foram calculados os intervalos para o ordenamento dos dados no gráfico Box plot (Figura 3). Sendo eles (MEDRI, 2011):

- Valor Mínimo;

- Primeiro Quartil (Q1)

- Mediana (segundo quartil Q2)

- Terceiro Quartil (Q3)

- Valor Máximo

Os valores mínimo e máximo não necessitam de uma equação pois são os extremos do conjunto de dados, porém os quartis são definidos pela equação 1.

$$
Q_{i}=\frac{i}{4}(N+1)
$$

Eq. 1

Onde: 
i: representa qual quartil será calculado, ex: Quartil $1=1 / 4(N+1)$;

$\mathrm{N}$ : total de dados da série, ex: série de 2000 a 2010, logo 10 anos- Quartil $1=$ $1 / 4(10+1)$

Os valores acima citados são utilizados como intervalos do gráfico box plot, como pode ser visualizado na figura 3 . O box plot ou diagrama de caixa permite a divisão do conjunto de dados em quatro partes, a partir do cálculo dos quartis (Equação 1), dessa forma, cada uma dessas partes representa $25 \%$ do conjunto de dados. Com isso a caixa do box plot fica com $50 \%$ dos dados que mais se aproximam da mediana, os primeiros $25 \%$ maiores e menores que ela. Posteriormente calcula-se o alcance do "bigode" do gráfico com as equações dois (2) e três (3). A partir desta etapa os valores que ultrapassarem os limites superior e inferior são considerados outliers, os chamados "pontos fora da curva".

$$
\begin{array}{ll}
\text { Limite inferior: } \max \left\{\min (\text { dados }) ; Q_{1}-1,5\left(Q_{3}-Q_{1}\right)\right\} & \text { Eq. } 2 \\
\text { Limite superior: } \min \left\{\max (\text { dados }) ; Q_{3}+1,5\left(Q_{3}-Q_{1}\right)\right\} & \text { Eq. } 3
\end{array}
$$

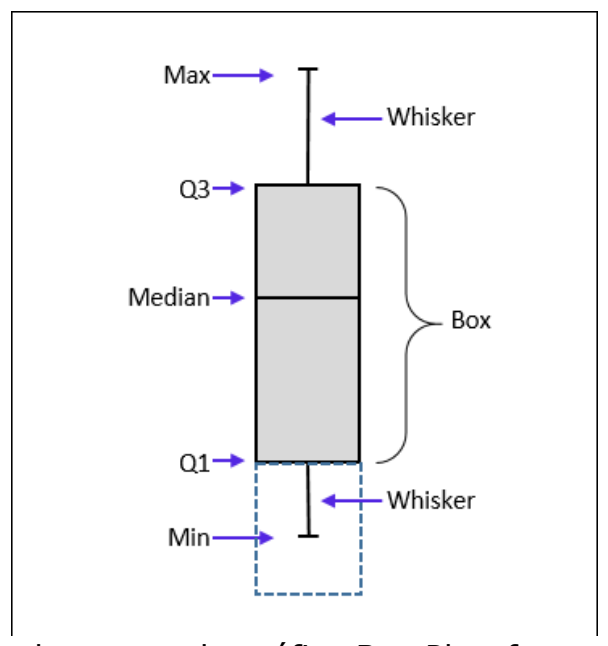

Figura 3 - Representação dos elementos do gráfico Box Plot, fonte: contextures.com

$\mathrm{Na}$ análise dos dados de precipitação a metodologia do box plot se apresenta como uma importante ferramenta estatística, uma vez que permite a análise de grandes conjuntos de dados. Os cálculos foram realizados a partir do software Microsoft Excel 2013, enquanto que os gráficos box plot foram gerados no software de estatísticas Past3 (HAMMER et al., 2001). Para uma análise histórica dos dados, foram feitos gráficos de distribuição de frequência com intervalos de 10 anos a partir de 1910 (início da série), sendo que o último intervalo ficou com 8 anos (2010 a 2017).

$\mathrm{Na}$ quarta fase, os meses foram classificados a partir dos dados referentes ao cálculo, segundo a metodologia proposta por Galvani e Luchiari (2004), a distribuição dos dados como seco, normal, chuvoso se daria a partir da posição dos valores no gráfico. Primeiramente, os valores compreendidos entre o valor mínimo e o primeiro quartil são considerados como meses secos, já os compreendidos dentro da caixa do box plot, ou seja, entre o quartil 1 (Q1) e o quartil 3 (Q3), são considerados normais ou habituais, e os meses classificados como maiores que o terceiro quartil (Q3), foram considerados chuvosos (Figura 04). 
Destaca-se que os valores $5 \%$ menores e maiores do conjunto de dados foram, respectivamente, considerados como super-secos e super-chuvosos (GALVANI E LUCHIARI, 2004). A disposição acima apresentada pode ser caracterizada pelo quadro 01.

Quadro 1 - Intervalos de classificação.

\begin{tabular}{|c|c|}
\hline Precipitação mensal $(\mathbf{m m})$ & Classificação \\
\hline $5 \%$ menores da série & Super secos \\
\hline $5 \%$ maiores da série & Super úmidos \\
\hline Entre $\vee$ min e $1^{\circ}$ quartil & Secos \\
\hline Entre $1^{\circ}$ quartil e $3^{\circ}$ quartil & Normais/habituais \\
\hline Entre $3^{\circ}$ quartil e $\vee$ máx. & Úmidos \\
\hline
\end{tabular}

Fonte: Galvani e Luchiari (2004).Adaptado pelos autores

A quinta etapa corresponde as análises de comparação entre as classificações dos totais anuais com a ação dos fenômenos ENOS e ODP e suas respectivas intensidades. Os dados referentes aos anos de atuação dos fenômenos ENOS (EI Niño e La Niña) com suas respectivas intensidades foram obtidos a partir do site CPTEC/INPE (http://enos.cptec.inpe.br/). Esta comparação foi realizada a partir dos dados classificados pela técnica do Box Plot e as indicações de intensidade do fenômeno ENOS, tal como fora aplicada por Oliveira (2016) e Caldana et al (2019).

Para a comparação dos períodos de dados com a ODP foram utilizados os dados de seu monitoramento desenvolvido pela NOAA National Oceanic and Atmospheric Administration, disponibilizado por meio do site http://research.jisao.washington.edu/pdo/PDO.latest.

\section{RESULTADOS E DISCUSSÃO}

\subsection{VARIABILIDADES ANUAL DAS CHUVAS E SUA RELAÇÃO COM OS FENÔMENOS ENOS E ODP}

Os totais anuais para o município de Juiz de Fora (MG) foram caracterizados como habituais se estivessem entre 1281,1 e $1700,3 \mathrm{~mm}$ sendo que abaixo de $1281,1 \mathrm{~mm}$ foram classificados como os anos secos e acima dos $1700,3 \mathrm{~mm}$ os anos chuvosos (Figura 4). É possível observar ainda a alta variabilidade dos dados ao longo do período, sendo de $694,4 \mathrm{~mm}$ no ano mais seco (1970) e $2265,3 \mathrm{~mm}$ no ano mais chuvoso (1983). 


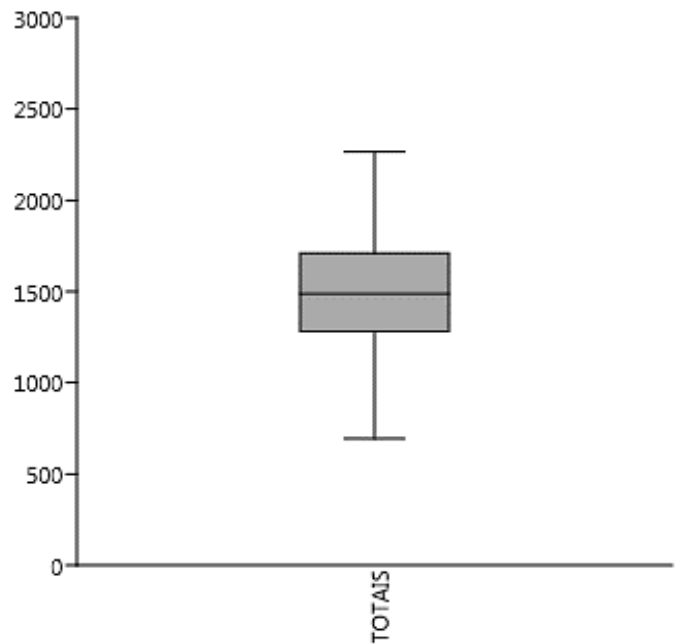

Figura 4 - Gráfico box plot para os totais anuais. Organizado pelos autores.

A figura 5 demonstra a variabilidade dos dados ao longo das décadas, sendo assim é possível notar alguns períodos secos, como as décadas de 1910$19,1950-59,1990-99$. Além dos períodos mais chuvosos, como a década de 1920-29 e a partir dos anos 2000, com apenas 3 anos secos (e/ou super-secos) nos últimos 18 anos. Evidencia-se que por grandes períodos os dados anuais se comportam dentro da habitualidade, sendo que a partir da década de 1980 observa-se uma diminuição na frequência dos anos habituais.

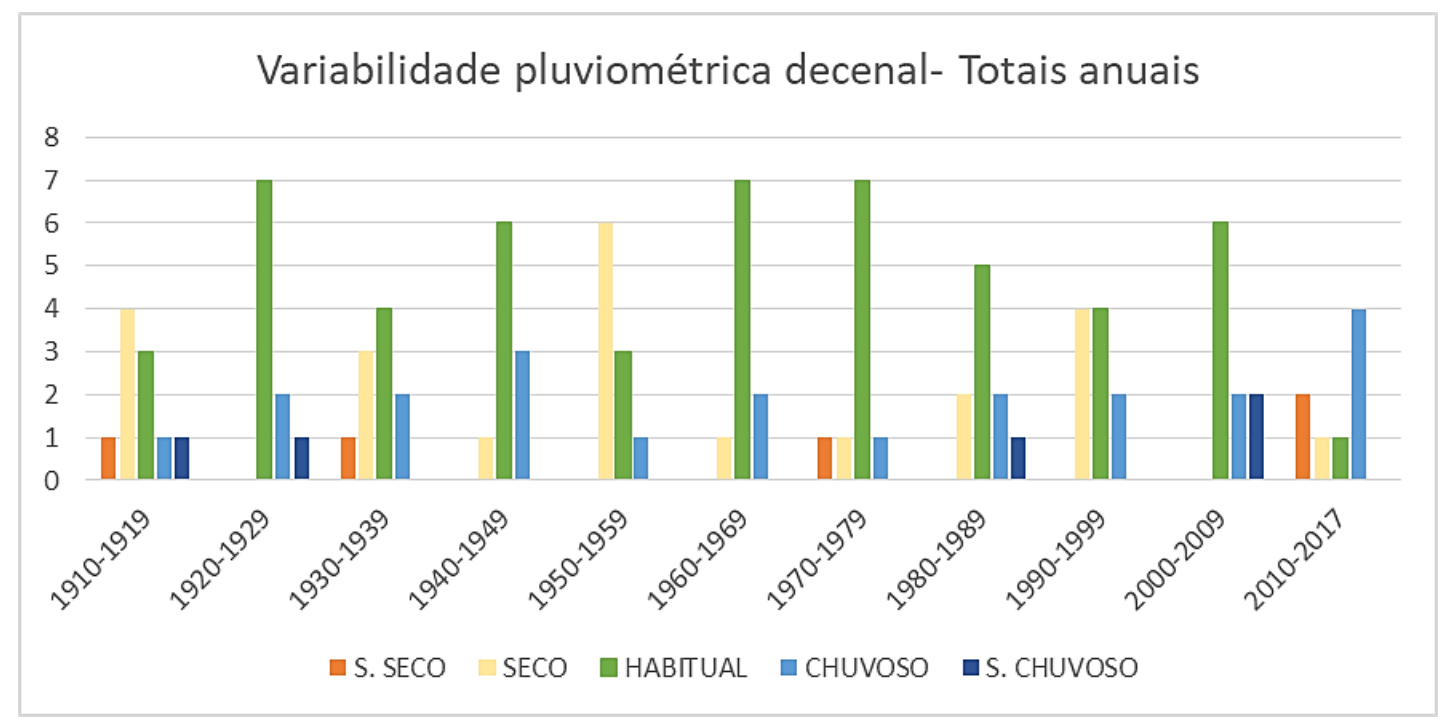

Figura 5 - Variabilidade decenal dos totais pluviométricos anuais em Juiz de Fora(MG). Organizado pelos autores.

As precipitações anuais nos últimos 10 anos (2008-2017), tem demonstrado uma diminuição da habitualidade nos dados (Tabela 1), nesse período apenas um ano (2012) se caracterizou como Normal/Habitual, os outros nove anos se dividiram em seis anos Chuvosos (2008, 2009, 2010, 2011, 2013 e 2016) sendo que o ano de 2008 foi considerado Super-Chuvoso, além disso, três anos foram considerados Secos (2014, 2015, 2017) sendo que 2014 $(930,4 \mathrm{~mm})$ e 2017 (946,9mm) estão entre os mais secos da série analisada. 
Tabela 1 - Classificação dos últimos 10 anos, para os totais anuais.

\begin{tabular}{cc} 
Ano & $\begin{array}{c}\text { Total pluviométrico } \\
(\mathrm{mm})\end{array}$ \\
\hline 2008 & 2185,7 \\
2009 & 1786,5 \\
2010 & 1731,7 \\
2011 & 1715,0 \\
2012 & 1363,7 \\
2013 & 1737,4 \\
2014 & 930,4 \\
2015 & 1281,0 \\
2016 & 1731,9 \\
2017 & 946,9 \\
\hline
\end{tabular}

Organizado pelos autores.

Grimm (2009) destacou que os principais modos de influência na variabilidade que atuam no Brasil são os fenômenos El Niño e La Niña. Nesse sentido, o quadro 2 aponta para cada ano da série analisada as respectivas classificações dos anos em: super chuvoso, chuvoso, normal/habitual, seco e super seco e a ocorrência de eventos El Niño e La Niño com suas respectivas intensidades (fraco (a), forte e moderado (a) para os anos estudados, segundo o CPTE/INPE (http://enos.cptec.inpe.br/). 
Quadro 2 - Correlação entre as classificações dos anos (SC. S. H. C. SC.) e ação dos fenômenos El Niño e La Niña com suas respectivas intensidades.

\begin{tabular}{|c|c|c|c|c|c|c|c|c|c|c|c|c|c|c|c|}
\hline \multirow{2}{*}{ Ano } & \multirow{2}{*}{ Class. } & \multicolumn{2}{|c|}{ ENOS } & \multirow{2}{*}{ Ano } & \multirow{2}{*}{ Class. } & \multicolumn{2}{|c|}{ ENOS } & \multirow{2}{*}{ Ano } & \multirow{2}{*}{ Class. } & \multicolumn{2}{|c|}{ ENOS } & \multirow{2}{*}{ Ano } & \multirow{2}{*}{ Class. } & \multicolumn{2}{|c|}{ ENOS } \\
\hline & & EN & $\mathrm{LN}$ & & & $\mathrm{EN}$ & $\mathrm{LN}$ & & & $\mathrm{EN}$ & $\mathrm{LN}$ & & & $E N$ & $\mathrm{LN}$ \\
\hline 1910 & 1166,1 & Neutro & Fraca & 1937 & 1772,6 & Neutro & Fraca & 1964 & 1622,7 & Moderado & Fraca & 1991 & 1579,5 & Forte & Neutro \\
\hline 1911 & 1214,5 & Moderado & Fraca & 1938 & 1763,0 & Neutro & Fraca & 1965 & 1935,6 & Forte & Fraca & 1992 & 1794,0 & $\begin{array}{c}\text { Forte/Fra } \\
\text { co }\end{array}$ & Neutro \\
\hline 1912 & 1612,7 & Moderado & Neutro & 1939 & 946,0 & Moderado & Fraca & 1966 & 1658,2 & Forte & Neutro & 1993 & 1221,2 & Fraco & Neutro \\
\hline 1913 & 1424,2 & Fraco & Neutro & 1940 & 1637,7 & $\begin{array}{c}\text { Moda/For } \\
\text { te }\end{array}$ & Neutro & 1967 & 1595,5 & Neutro & Moderada & 1994 & 1722,5 & Neutro & Neutro \\
\hline 1914 & 1103,8 & Fraco/Mod. & Neutro & 1941 & 1550,3 & $\begin{array}{c}\text { Forte/Fra } \\
\text { co }\end{array}$ & Neutro & 1968 & 1286,9 & Fraco & Moderada & 1995 & 1596,6 & Neutro & Neutro \\
\hline 1915 & 977,3 & Fraco/Mod. & Neutro & 1942 & 1768,7 & Fraco & Forte & 1969 & 1504,0 & Fraco/Mod. & Moderada & 1996 & 1566,0 & Neutro & Neutro \\
\hline 1916 & 2122,2 & Neutro & Forte & 1943 & 1713,8 & Neutro & Forte & 1970 & 694,2 & Moderado & Moderada & 1997 & 1211,8 & Forte & Neutro \\
\hline 1917 & 1213,5 & Neutro & $\begin{array}{c}\text { Forte/Mo } \\
\text { d. }\end{array}$ & 1944 & 1523,6 & Neutro & Neutro & 1971 & 1284,6 & Neutro & Neutro & 1998 & 1274,0 & Forte & Fraca \\
\hline 1918 & 1445,3 & Forte & Moderada & 1945 & 1327,8 & Neutro & Neutro & 1972 & 1483,2 & Forte & Neutro & 1999 & 1356,1 & Neutro & Fraca/Mod. \\
\hline 1919 & 1839,5 & Forte/Mod. & Neutro & 1946 & 1054,1 & Neutro & Neutro & 1973 & 1824,3 & Forte & Neutro & 2000 & 1451,2 & Neutro & Moderada \\
\hline 1920 & 1603,3 & Moderado & Neutro & 1947 & 1791,2 & Neutro & Neutro & 1974 & 1343,9 & Neutro & Neutro & 2001 & 1565,2 & $\begin{array}{l}\text { Neutro } \\
\end{array}$ & Neutro \\
\hline 1921 & 1289,9 & Neutro & Neutro & 1948 & 1444,5 & Neutro & Neutro & 1975 & 1473,2 & Neutro & Neutro & 2002 & 1444,6 & Moderado & Neutro \\
\hline 1922 & 1632,6 & Neutro & Neutro & 1949 & 1566,9 & Neutro & Forte & 1976 & 1678,5 & Moderado & Neutro & 2003 & 1892,3 & Moderado & Neutro \\
\hline 1923 & 1691,6 & Neutro & Neutro & 1950 & 1412,0 & Neutro & Forte & 1977 & 1182,0 & Moderado & Neutro & 2004 & 2112,4 & Neutro & Neutro \\
\hline 1924 & 2240,6 & Neutro & Moderado & 1951 & 1241,1 & Moderado & Neutro & 1978 & 1420,6 & Neutro & Neutro & 2005 & 1575,7 & Neutro & Neutro \\
\hline 1925 & 1325,5 & Moderado & Moderado & 1952 & 1904,2 & $\begin{array}{c}\text { Moda/Fra } \\
\text { co }\end{array}$ & Neutro & 1979 & 1605,6 & Moderado & Neutro & 2006 & 1517,8 & Moderado & Neutro \\
\hline 1926 & 1834,5 & Moderado & Neutro & 1953 & 1263,6 & Fraco & Neutro & 1980 & 1260,9 & Moderado & Neutro & 2007 & 1457,7 & Moderado & Moderada \\
\hline 1927 & 1348,9 & Neutro & Neutro & 1954 & 1154,2 & Neutro & Fraca & 1981 & 1321,8 & Neutro & Neutro & 2008 & 2185,7 & $\begin{array}{l}\text { Neutro } \\
\end{array}$ & Moderada \\
\hline 1928 & 1281,8 & Neutro & Neutro & 1955 & 1262,7 & Neutro & Fraca/Mod. & 1982 & 1777,3 & Forte & Neutro & 2009 & 1786,5 & Moderado & Neutro \\
\hline 1929 & 1907,0 & Neutro & Neutro & 1956 & 1277,5 & Neutro & Moderada & 1983 & 2265,5 & Forte & Neutro & 2010 & 1731,7 & Moderado & Moderada \\
\hline 1930 & 1195,8 & Forte & Neutro & 1957 & 1695,9 & Forte & Neutro & 1984 & 1456,0 & Neutro & Neutro & 2011 & 1715,0 & Neutro & Moderada \\
\hline 1931 & 1445,5 & Forte & Neutro & 1958 & 1452,3 & Forte & Neutro & 1985 & 2102,6 & Neutro & Neutro & 2012 & 1363,7 & Neutro & Neutro \\
\hline 1932 & 1492,6 & Neutro & Neutro & 1959 & 1241,9 & Neutro & Neutro & 1986 & 1567,1 & Moderado & Neutro & 2013 & 1737,4 & Neutro & Neutro \\
\hline 1933 & 1026,7 & Neutro & Moderada & 1960 & 1645,2 & Neutro & Neutro & 1987 & 1509,1 & $\begin{array}{l}\text { Mada/For } \\
\text { te }\end{array}$ & Neutro & 2014 & 930,4 & Neutro & Neutro \\
\hline 1934 & 1375,8 & Neutro & Moderada & 1961 & 2080,6 & Neutro & Neutro & 1988 & 1452,1 & Forte & Moderada & 2015 & 1281,0 & Forte & Neutro \\
\hline 1935 & 1558,0 & Neutro & Neutro & 1962 & 1686,7 & Neutro & Neutro & 1989 & 1281,1 & Neutro & Moderada & 2016 & 1731,9 & Forte & Neutro \\
\hline 1936 & 1253,2 & Neutro & Neutro & 1963 & 1067,9 & Moderado & Neutro & 1990 & 1079,5 & Neutro & Neutro & 2017 & 946,9 & Neutro & Moderada \\
\hline
\end{tabular}

\begin{tabular}{|c|c|c|c|c|c|c|}
\hline \multicolumn{7}{|c|}{ Classificaçã̃o } \\
\hline & SC & Super-chuxoso & $\mathrm{C}$ & Chuvoso & $\mathbf{H}$ & Habitual \\
\hline & $\mathbf{S}$ & Seco & SS & Super-seco & & \\
\hline
\end{tabular}


É possível verificar que entre os anos Super-Chuvosos (1924, 1983 e 2008), apenas o ano de 1983 corresponde à ação do fenômeno El Niño forte, nos demais, o fenômeno encontra-se na sua fase neutra. Para esses anos, o fenômeno La Niña apresentou-se, respectivamente, como moderada, neutra, moderada. Os anos super secos (1939, 1970 e 2014) verificou-se que fenômenos El Niño e La Niña se apresentaram como EN- moderado e LN- fraca (1939), EN- moderado e LN fraca (1970), EN- neutro e LN- neutra (2014).

Para os anos em que houve ações do fenômeno EN forte verificou-se que 11 anos corresponderam a anos Habituais/Normais (1918, 1931, 1940, 1941, $1957,1958,1966,1972,1987,1988$ e 1991), seis anos corresponderam à anos chuvosos (1919, 1965, 1973, 1982, 1992 e 2016), um ano apresentou-se como super chuvoso (1983) e quatro anos foram secos (1930, 1997, 1998 e 2015). Para os eventos de La Niña forte, três anos foram chuvosos (1916, 1942 e 1943), um seco (1917) e dois anos apresentaram-se como habituais (1949 e 1950).

Isso posto, não é possível estabelecer, a partir das classificações adotadas no presente trabalho, correlação direta entre os anos Super-Chuvosos e/ ou Super-secos aos fortes eventos de El Niño e La Niña, e assim identificar direta correlação entre o modo de variabilidade ENOS na variabilidade das chuvas para o município de Juiz de Fora.

A figura 06 apresenta as décadas estudadas com suas respectivas frequências de anos Super Secos, Secos, Habituais, Chuvosos e Super Chuvosos, e a média de variação da ODP (Oscilação Decadal do Pacífico). É possível verificar, assim como nas análises das correlações entre os limiares de classificação dos anos com o ENOS, que a ODP não apresenta correlação como modo de variabilidade direta com as chuvas para a área estudada.

Observa-se que durante a fase fria (negativa) da ODP (1946-1979) (MANTUA et al., 1997), apenas a década de 1950-1959 (ODP: -8,1) que apresentou a maior parte dos anos Secos. Nas décadas seguintes (1960-1969 e 1970-1979), ainda durante a fase fria da ODP, a pluviosidade anual foi em sua maioria considerada como Habitual.

Da mesma forma, durante a fase quente da ODP (1979-1999) (MANTUA et al., 1997), a maioria dos anos na década e 1980-1989 (ODP: 9,5) foram considerados como Habituais e, na década de 1990-1999 (ODP: 4,0), a frequência e anos considerados como Secos foi a mesma dos anos Chuvosos.

Outro aspecto que merece destaque é que havia uma expectativa de que a partir de 1999 a ODP entrasse em uma nova fase fria. No entanto, nem os dados pluviométricos de Juiz de Fora, nem os índices da ODP sugerem correlação um com o outro. Durante a década de 2000-2009 (ODP: -1,3) as chuvas anuais em Juiz de Fora foram consideradas como Habituais, Chuvosos e Super Chuvosos e, no período de 2010-2017 (ODP: 2,4) ocorreram contrastes entre os anos considerados como Super Secos, Secos e Chuvosos.

Em uma condição em que a ODP modulasse a variabilidade das chuvas em Juiz de Fora, esperaria-se que nos anos de maior variação negativa, os anos Secos e Super Secos predominassem, enquanto que na fase positiva os anos Chuvosos e Super Chuvosos fossem maioria nos recortes temporais. Com isso, da mesma forma como ocorrido com o fenômeno ENOS, não é possível 
estabelecer correlação direta entre a variabilidade das chuvas e a ODP para Juiz de Fora.

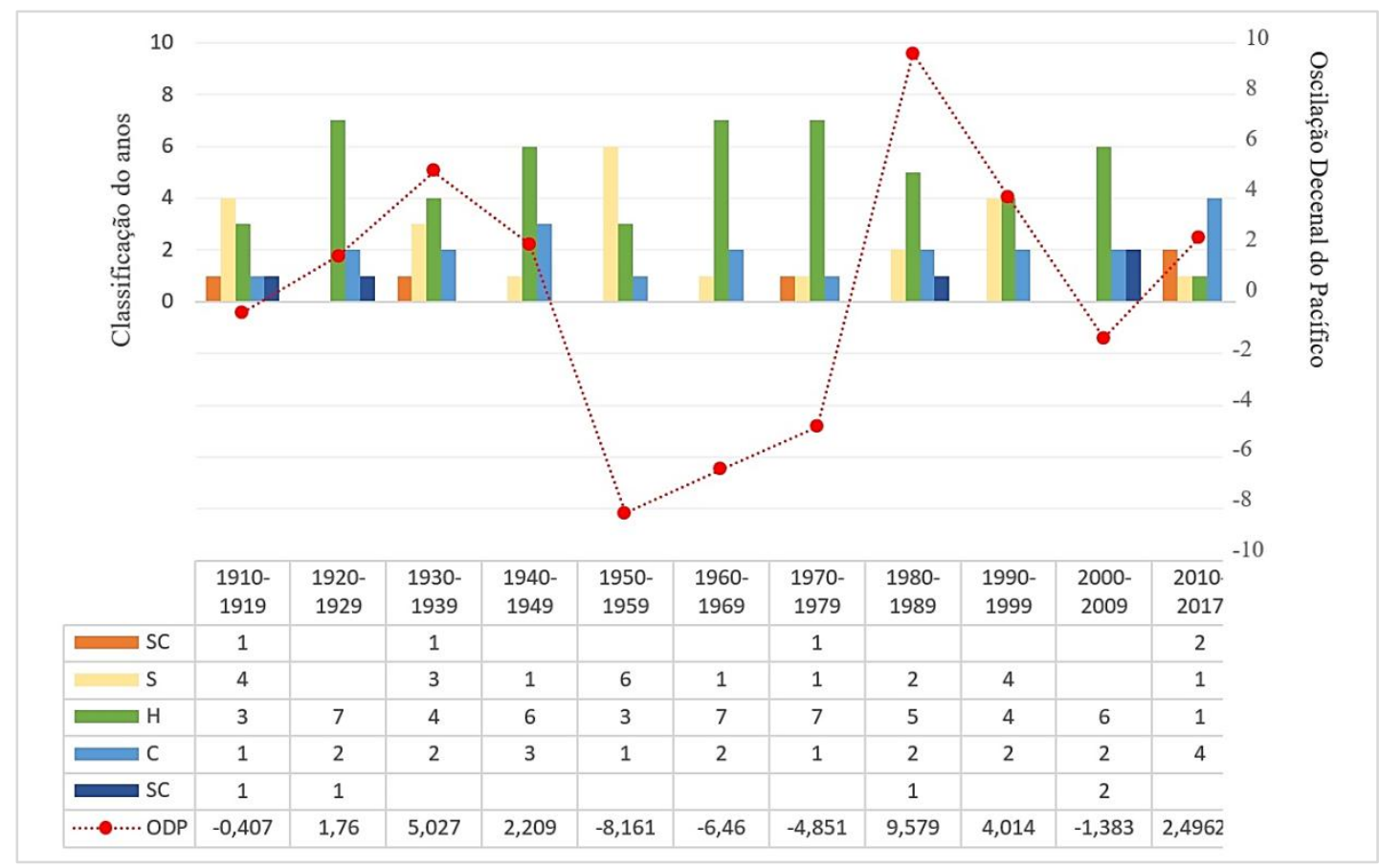

Figura 06 - Correlação entre as classificações dos anos nos períodos analisados e sua relação com as fases (positiva e negativa) da Oscilação Decadal do Pacífico (ODP), SC (super chuvoso), S (seco), H (habitual,) C (chuvoso), SC (super chuvoso). Organizado pelos autores.

\subsection{ANÁLISE DOS TOTAIS PLUVIOMÉTRICOS TRIMESTRAIS}

A figura 07 apresenta o gráfico box plot para os recortes trimestrais em Juiz de Fora destacando que o período do verão (JFM) representa em média $44,4 \%$ dos totais pluviométricos, seguindo pela Primavera (OND) com 40,6\% o Outono (AMJ) com $8,8 \%$ e o Inverno (JAS) com $6,1 \%$ das precipitações, demonstrando a variabilidade anual e sazonal dos dados. 


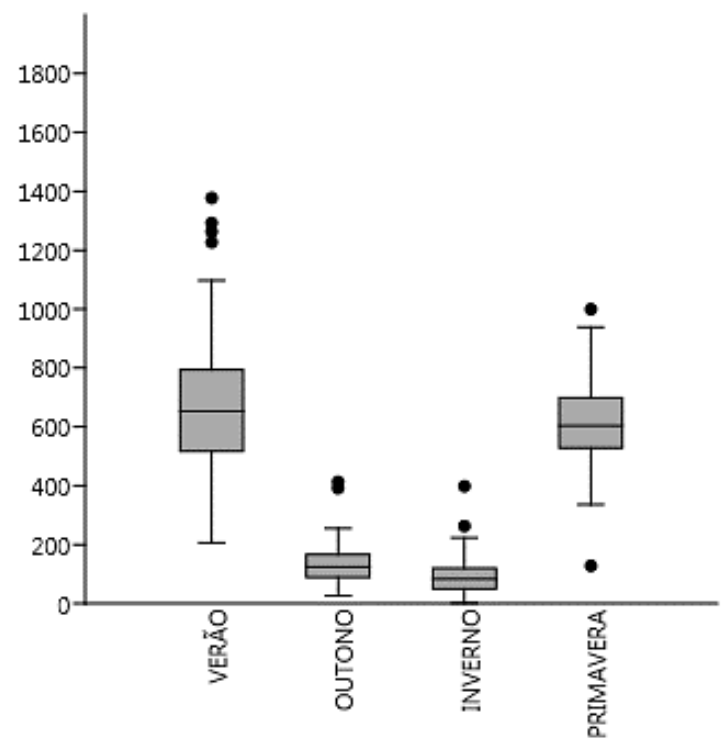

Figura 07 - Box plot trimestral para os dados de Juiz de Fora (MG). Organizado pelos autores.

Representando cerca de $44,4 \%$ dos totais pluviométricos anuais, o verão (JFM) apresenta, em média $667,5 \mathrm{~mm}$ de precipitação e uma mediana de $653,5 \mathrm{~mm}$, além disso, foi observado o valor máximo de 1377,7 (em 1961) e o valor mínimo de 205,9 (em 1971). Iniciando o período seco, o Outono (AMJ) representa $8,8 \%$ do total pluviométrico anual, apresentando média de $132,1 \mathrm{~mm}$, uma mediana de $124,2 \mathrm{~mm}$, com um valor máximo de $412,9 \mathrm{~mm}$ (em 1983) e um valor mínimo de 25,8mm no ano de 1959 (Tabela 2).

Tabela 02 - Classes do box plot para os dados trimestrais da série Juiz de Fora (19102017).

\begin{tabular}{ccccc} 
& VERÃO & OUTONO & INVERNO & PRIMAVERA \\
\hline MÁXIMO & 1377,7 & 412,9 & 398,3 & 999,7 \\
$3^{\circ}$ QUARTIL & 793,2 & 165,2 & 119,3 & 693,3 \\
MEDIANA & 653,5 & 124,2 & 83,3 & 603,8 \\
$1^{\circ}$ QUARTIL & 517,9 & 89,1 & 49,4 & 528,3 \\
MÍNIMO & 205,9 & 25,8 & 0,6 & 127,9 \\
\hline
\end{tabular}

Organizado pelos autores

No inverno (JAS) as chuvas representam, em média, 6,1\% da precipitação anual com um total pluviométrico médio de $92,3 \mathrm{~mm}$, e uma

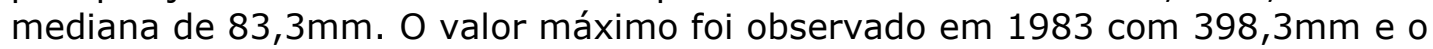
valor mínimo, de 0,6mm, em 1955. Deve-se destacar que o ano de 1983, o mais chuvoso da história, teve, também, a estação seca mais chuvosa já registrada, representando os valores máximo de precipitação do Outono (AMJ) e do Inverno (JAS).

Marcando o retorno da estação chuvosa, a primavera (OND) compreende em média $40,6 \%$ da precipitação anual com média de $610,7 \mathrm{~mm}$, e uma mediana de $603,8 \mathrm{~mm}$. Seu valor máximo foi observado no ano de 2008 , com 999,7mm e, seu valor mínimo de 127,9mm em 1970 (Tabela 2). 
Devido à representatividade das precipitações da primavera e do verão para os totais anuais, todos os anos considerados Super Secos tiveram o verão e/ou a primavera Secos ou Super-secos.

O ano de 1970, considerado o mais seco da história, com 694,2 mm, teve um verão seco, com $387,8 \mathrm{~mm}$ e uma primavera super-seca com 127,9mm; o menor valor registrado na série histórica para a estação.

Analisando a variabilidade decenal dos dados para o verão (JFM) (Figura 08), é possível observar no período entre 1980 e 2009 um aumento das chuvas e, consequentemente, uma redução na ocorrência de períodos secos. Enquanto que no período de 1910 a 1979 houve uma intercalação entre décadas secas (1910-19;1930-39;1950-59;1970-79) e mais chuvosas (1920-29; 1940-49; 1960-69), sendo o período de 1920-29 o mais chuvoso do período. Nos últimos oito anos do período analisado (2010-17) ocorreram verões mais secos, sendo os de 2014 e 2017 considerados Super-Secos. O ano de 2014 teve o segundo menor total pluviométrico registrado na série, com $287,5 \mathrm{~mm}$, superado apenas pelo o verão de $1971 \mathrm{com}$ 205,9mm, sendo que este ano ficou marcado pelos problemas com abastecimento de água em diversas cidades do sudeste brasileiro, inclusive Juiz de Fora.

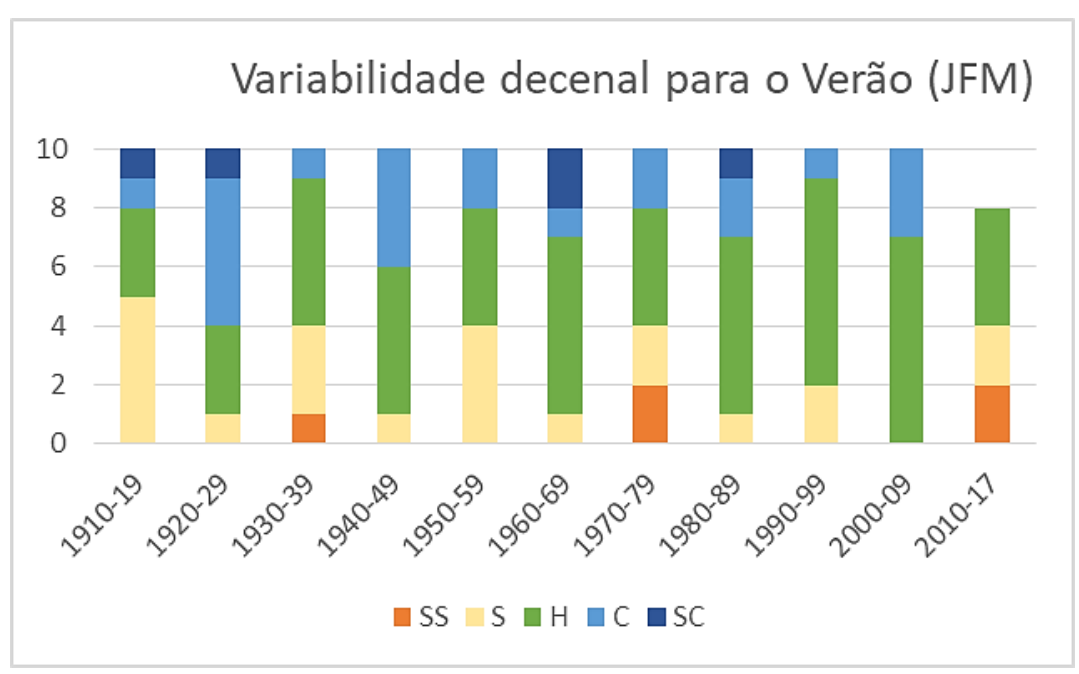

Figura 08 - Variabilidade decenal dos totais pluviométricos para o Verão (JFM). Organizado pelos autores.

O período do outono (AMJ) teve no intervalo de 1970 a 2009 um aumento na ocorrência de outonos Secos, sendo que esta condição não se manteve após 2010. No período mais recente (2010 a 2017) a estação tende a ser Chuvosa. Nos períodos de 1940-1949 e 1950-1959 é possível identificar uma diminuição na ocorrência de anos Normais/Habituais, quando comparadas ao início da série histórica, onde as precipitações se comportavam dentro da habitualidade. Exemplo disso, pode ser observado nas décadas de 1920-29 e 1930-39, as quais tiveram sete e oito anos, respectivamente, considerados como Habituais (Figura 09). 


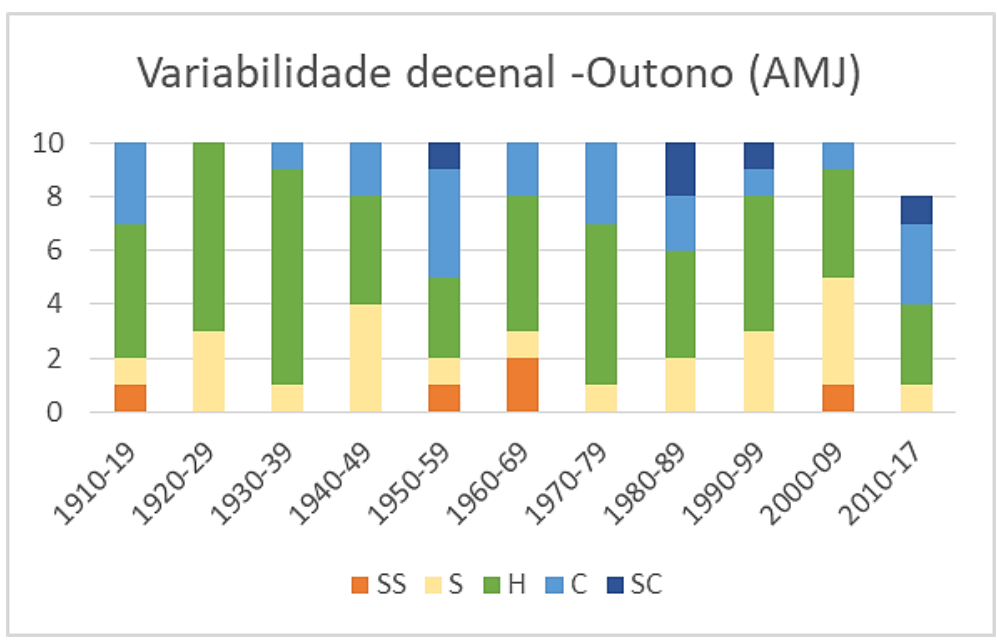

Figura 09 - Variabilidade decenal dos totais pluviométricos para o Outono (AMJ). Organizado pelos autores.

O inverno (JAS), com a menor representação pluviométrica trimestral da série, teve uma variabilidade decenal (Figura 10) na qual observa-se que no período entre 1940 a 1970 houve uma diminuição na habitualidade dos dados, apresentando décadas principalmente mais secas. Deve-se destacar para a década de 1940 a 1949 na qual ocorreram três extremos, sendo dois SuperChuvosos (1941 com 223,1mm e 1947 com 220,1) e um Super-Seco (7,4mm em 1949).

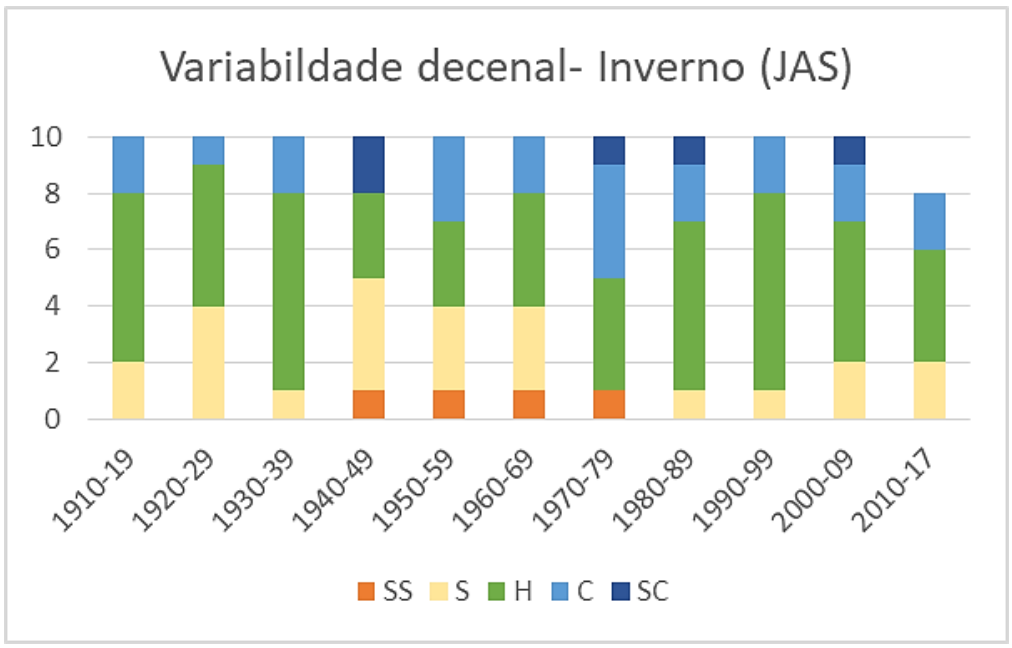

Figura 10 - Variabilidade decenal dos totais pluviométricos para o Inverno (JAS). Organizado pelos autores.

Já, a partir da década de 1980 até 2010 os períodos Habituais passaram a ocorrer com maior frequência, sendo que pelo menos cinco anos por década o período de inverno foi considerado Normal/Habitual, intercalando invernos secos e chuvosos. Nos últimos 18 anos houveram quatro invernos considerados Secos, cinco Chuvosos, sendo um deles Super Chuvosos e nove períodos normais/habituais, demonstrando quantitativamente as relações entre os períodos Secos, Habituais e Chuvosos. 
Representando a entrada (o retorno) da estação chuvosa, com mais de $40 \%$ da pluviosidade anual, observou-se que na Primavera (OND), até a década e 1960, houve maior frequência de períodos Secos (388,0 mm em 1915; $390,7 \mathrm{~mm}$ em 1927; 335,7 mm em 1951- o mais seco da série) em relação aos Chuvosos (Figura 11).

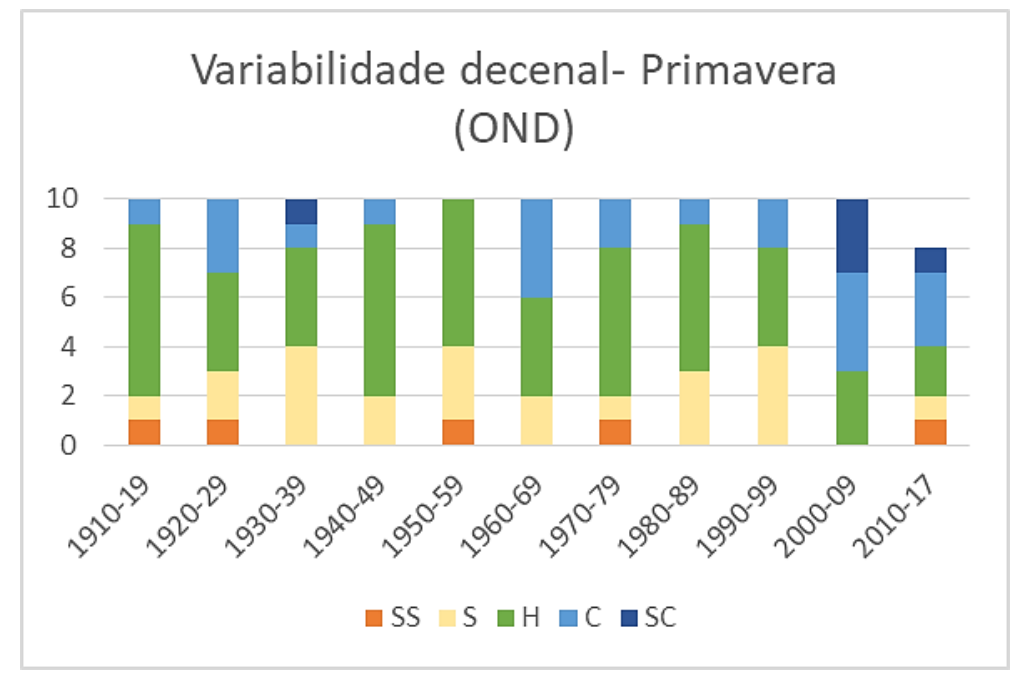

Figura 11 - Variabilidade decenal dos totais pluviométricos para a Primavera (OND). Organizado pelos autores.

No período de 1960 a 1999 ocorreram primaveras ainda mais secas, no entanto observa-se que o número de períodos chuvosos aumentou, sendo que, a partir dos anos 2000 a estação tem sido, em grande medida, chuvosa. A partir do quadro 05, é possível notar o número de períodos chuvosos, principalmente até 2011. Destaque deve ser dado ao ano de 2008, o qual teve o maior total pluviométrico registrado para esse período $(999,7 \mathrm{~mm})$. 
Tabela 03 - Totais pluviométricos trimestrais para a primavera (OND) no período de 2000 a 2017.

\begin{tabular}{cc} 
Ano & Total pluviométrico $(\mathrm{mm})$ \\
\hline 2000 & 591,0 \\
2001 & 794,8 \\
2002 & 736,6 \\
2003 & 739,8 \\
2004 & 880,2 \\
2005 & 604,5 \\
2006 & 801,5 \\
2007 & 572,3 \\
2008 & 999,7 \\
2009 & 906,5 \\
2010 & 863,6 \\
2011 & 764,8 \\
2012 & 528,8 \\
2013 & 720,2 \\
2014 & 411,7 \\
2015 & 579,5 \\
2016 & 813,2 \\
2017 & 397,4 \\
\hline
\end{tabular}

Organizado pelos autores.

Esses resultados corroboram com os observados em Oliveira et al (2018), os quais apontaram que os meses de novembro e dezembro tem apresentado tendência de aumento no volume das precipitações no município de Juiz de Fora.

\section{CONSIDERAÇÕES FINAIS}

A metodologia do box plot, conforme já atestam Galvani e Luchiari (2004) e Schneider e Silva (2014), apresenta-se como viável, uma vez que classifica os anos/meses entre Secos e Super Secos, Habituais/Normais, Chuvosos e Super Chuvosos de maneira rápida e objetiva, convergindo para os propósitos da Climatologia Geográfica, favorecendo pesquisas apoiadas na análise rítmica.

Considerando que modos de variabilidade podem influenciar nas chuvas de determinada área e, assim como aponta Grimm (2009), que o ENOS é um dos principais modos de variabilidade para o Brasil, a correlação não foi estabelecida para os dados totais anuais de Juiz de Fora. 
Da mesma forma, não foi possível correlacionar as décadas mais chuvosas (SC) e as mais secas (SS) à Oscilação Decadal do Pacífico, atestando, portanto, que as chuvas em Juiz de Fora não são moduladas diretamente nem pelo fenômeno ENOS, nem pela ODP.

Os dados trimestrais apontam para uma sazonalidade bem marcada das chuvas em Juiz de Fora, com mais de $80 \%$ da precipitação anual, em média, concentrada nos períodos de primavera (OND) e verão (JFM).

A análise trimestral dos dados permitiu visualizar a variabilidade dos dados ao longo da série, destacando décadas mais chuvosas e mais secas. Nos últimos 18 anos, os verões se comportaram principalmente dentro da habitualidade, intercalados, de maneira acessória, por períodos Secos e SuperSecos e, por períodos Chuvosos. No mesmo período, verifica-se alternância de outonos Secos e Chuvosos (2001-2009) e, após 2010, o predomínio de outonos mais Chuvosos.

Os invernos Habituais têm sido mais frequentes nos últimos 18 anos se comparados às décadas do século XX. Já as Primaveras mostraram-se mais Chuvosas neste século do que no século passado. Esta condição pode estar relacionada à maior ocorrência de eventos pluviométricos de grande intensidade (eventos extremos).

As confirmações das mudanças de comportamento nas chuvas em Juiz de Fora podem, ou não, serem atestadas por outros testes estatísticos mais específicos, pois os anos Chuvosos e Secos merecem atenção quando observamos os impactos que podem causar à sociedade.

\section{AGRADECIMENTOS}

Agradecemos à CAPES pela concessão de bolsas de mestrado aos dois primeiros autores do presente trabalho.

\section{REFERÊNCIAS}

ABREU, M. L. Climatologia da estação chuvosa de Minas Gerais: de Nimer (1977) à Zona de Convergência do Atlântico Sul. Geonomos, 6 (2): 17-22, 1998.

AB' SÁBER, A. Geomorfologia do Sítio Urbano de São Paulo. Cotia- SP: Ateliê Editorial, 2007.

ANA - Agência Nacional de Águas. Diretrizes e análises recomendadas para a consistência de dados pluviométricos /Agência Nacional de Águas; Superintendência de Gestão da Rede Hidrometeorológica. -- Brasília: ANA, SGH, 2011

BALDO, M.C. Variabilidade pluviométrica e a dinâmica atmosférica na bacia hidrográfica do rio Ivaí-PR- Tese de Doutorado, UNESP, Presidente PrudenteSP, 2006.

BARROS, J. R.; ZAVATINI, J. A. Bases conceituais em Climatologia Geográfica. Mercator - Revista de Geografia da UFC, ano 08, N. 16, 2009. 
BEREZUK, A. G.; GARCIA, M. R. Estudo de tendências do ritmo pluviométrico da bacia hidrográfica do rio Pardo- MS. Revista Brasileira de Climatologia, Ano 7, Vol. 9, JUL/DEZ/2011.

BORSATO, V. A dinâmica climática do Brasil e massas de ares. Curitiba-PR:CRV, 2016.

CALDANA, N. F. S; MARTELÓCIO, A. C.; RUDKE, A. P.; NITSCHE, P. R.; CARAMORI, P. H. Frequência, intensidade e variabilidade pluviométrica na mesorregião sudoeste Paranaense. Revista Brasileira de Climatologia, v. 25, n.15, p. 161-181, 2019.

CAVALCANTI, I.F.A.; FERREIRA, N.J.; DA SILVA, M.G.A.J.; SILVA DIAS, M.A.F. Tempo e Clima no Brasil. São Paulo: Oficina de Textos, 2009.

CHIERICE, R. A. F. Variabilidade espacial e temporal de precipitação pluviométrica na bacia hidrográfica do rio Mogi Guaçu. Tese de doutorado (em Geociências e Meio Ambiente), UNESP, Rio Claro- SP, 2013.

EDUARDO, C. C. Cartografia geomorfológica comparada: aplicações no município de Juiz de Fora-MG como subsidio ao planejamento. Dissertação de Mestrado (em Geografia), Instituto de Ciências Humanas- ICH, Universidade Federal de Juiz de Fora, Juiz de Fora, 2018.

FERREIRA, C.C.M. Estudo do comportamento do período chuvoso em Juiz de Fora-MG. Revista Geonorte. UFAM, V.1, N.5, 2012, p. 953-963.

GALVANI, E. e AZEVEDO, T.R. A Frente Polar Atlântica e as características de tempo associadas:

Estudo de caso. Textos do Laboratório de Climatologia e Biogeografia Departamento de Geografia /

FFLCH / USP - Série TA - Texto 018 disponível em: http://www.geografia.fflch.usp.br/inferior/laboratorios/lcb/az/TA018. pdf, 2012.

GALVANI, E; LUCHIARI, A. Critérios para classificação de anos com regime pluviométrico normal, seco e úmido. In: VI Simpósio Brasileiro de Climatologia Geográfica, Aracajú, 2004, anais, p. 20-29.

GRIMM, A.M. Variabilidade interanual do Clima no Brasil. In: CAVALCANTI, I.F.A.; FERREIRA, N.J.; DA SILVA, M.G.A.J.; SILVA DIAS, M.A.F. Tempo e Clima no Brasil. São Paulo: Oficina de Textos, 2009.

HAMMER, Ø.; HARPER, D.A.T.; RYAN, P.D. Paleontological Statistics Software Package for Education and Data Analysis. Palaeontologia Electronica 4(1): 9pp 2001.

KAYANO, M.T.; ANDREOLI, R.V. Variabilidade decenal e multidecenal. In: CAVALCANTI, I.F.A.; FERREIRA, N.J.; DA SILVA, M.G.A.J.; SILVA DIAS, M.A.F. Tempo e Clima no Brasil. São Paulo: Oficina de Textos, 2009.

MANTUA, N.J.; HARE, S.R.; ZHANG, Y.; WALLACE, J.M.; FRANCIS, R. C. A Pacific Interdecadal Climate Oscillation with impacts on salmon production. Bulletin of the American Meteorological Society, v.78, p. 1069-1079, 1997.

MEDRI, W. Análise exploratória de dados. Curso de especialização em estatística, Centro de ciências exatas, Universidade estadual de Londrina- UEL, 2011. 
MENDONÇA, F.; DANNI-OLIVEIRA, I. M. Climatologia: noções básicas e climas do Brasil. São Paulo: Oficina dos textos, 2007.

MONTEIRO, C. A. F. Análise rítmica em climatologia. São Paulo: USP/ Instituto de Geografia, 1971.

A dinâmica climática e as chuvas do estado de São Paulo: estudo geográfico sob forma de atlas. São Paulo: IGEOG, 1973.

NASCIMENTO JR, L. Perspectivas da variabilidade climática. Geografia em questão, V. 10, N. 1, p. 95-114, 2017.

NOAA-NATIONAL OCEANIC AND ATMOSFERIC ADMINISTRATION. What is EI Niño \& La Niña? Junho de 2018. Disponível em https://www.weather.gov/media/owlie/2018_ENSO.pdf

OLIVEIRA, D. E. Participação dos sistemas atmosféricos na gênese e ritmos das chuvas na bacia hidrográfica do Rio Preto MG/RJ. Dissertação de mestrado (em geografia), Instituto de Ciências Humanas- ICH, Universidade Federal de Juiz de Fora, Juiz de Fora, 2016.

OliVeirA, T. A.; TAVARES, C. M. G. FERREIRA, C. C. M. Tendências das chuvas mensais no município de Juiz de Fora-MG. In: Simpósio Brasileiro de Climatologia Geográfica, 2018, Juiz de Fora, anais, p 1168- 1177.

REBOITA, M. S.; RodRIgueS, M.; SILVA, L. F.; ALVES, M. A. Aspectos climáticos do estado de Minas Gerais. Revista Brasileira de Climatologia, V. 17, Ano 11, p. 206-226, 2015.

SANTOS, V. J.; FIALHO, E. S. Zona de convergência do Atlântico Sul (ZCAS) e impactos pluviais intensos: o caso da cidade de Ubá-MG. Revista Brasileira de Climatologia, V. 19, Ano 12, p. 218-238, 2016.

SCHNEIDER, H. A geografia do clima na microrregião de Dourados- MS: regime e excepcionalidades pluviais no período de 1980 a 2012. Dissertação de mestrado (em Geografia), Universidade Federal de Grande Dourados- UFGD, 2014, 149f.

SCHNEIDER, H.; SILVA, C. A. O uso do modelo box plot na identificação de anos-padrão secos, chuvosos e habituais na microrregião de Dourados, Mato Grosso do Sul. Revista do Departamento de Geografia - USP, Volume 27 (2014), p. 131-146.

STAICO, J. A bacia do rio Paraibuna em Juiz de Fora-MG. Universidade Federal de Juiz de Fora, Juiz de Fora, 1976.

TAVARES, A. C. Critérios de escolha de anos padrões para análise rítmica. Geografia, 1 (1), abril de 1976. 